$\infty$

0

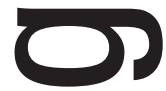

-

ת

1

$\longrightarrow$ 



\title{
O CARÁTER DIALÉTICO DA MODERNIZAÇÃO AGRÍCOLA BRASILEIRA E SUAS INSERÇÕES NOS GERAIS DE BALSAS-MA
}

\author{
THE DIALETIC CARATER OF THE BRAZILIAN AGRICULTURAL MODERNIZATION AND THEIR INSERTS IN THE \\ GENERAL OF BALSAS-MA
}

\section{EL CARÁCTER DIALÉTICO DE LA MODERNIZACIÓN AGRÍCOLA BRASILEÑA Y SUS INSERÇÕES EN LOS GENERALES DE BALSAS-MA}

\author{
Rosimary Gomes Rocha - Secretaria de Educação do Tocantins \\ rosegeografia@hotmail.com
}

\section{Resumo}

No Brasil, as formas de produção no campo encontram-se cada vez mais apoiadas na revolução técnico-científica, aspecto este que se acentuou a partir da década de 1970, período em que o Governo Militar implementou políticas públicas para a expansão da fronteira agrícola e consequentemente, da ocupação do Cerrado e da Amazônia brasileira. São espaços produtivos articulados à lógica global de produtividade, que possui como objetivo principal a produção de grãos. A região dos Gerais de Balsas se caracteriza como um desses espaços, evidenciado pelo intenso uso de máquinas, insumos e fertilizantes, que permitem um novo uso do tempo e do espaço. Estudar as mediações das relações sociais, bem como as bases sobre as quais essas mediações estão estabelecidas nos Gerais de Balsas, são de fundamental importância para o entendimento do (re)ordenamento territorial ocorrido na referida área.

Palavras-chave: Cerrado. Políticas Públicas. Território. Gerais de Balsas.

\section{Summary}

In Brazil the production forms in the field are more and more leaning in the technician-scientific revolution, logic aspect that that increases starting from the decade of 1970, period in that the Military Government implemented public politics for the expansion of the agricultural border and consequently of the occupation of the Savannah and of the Amazonian Brazilian. They are articulate productive spaces to the global logic of productivity that possesses as main objective the production of grains. The area of the General of Balsas is characterized as one of those spaces, evidenced by the intense use of machines, inputs and fertilizers, that you/they allow a new use of the time and of the space. To study the mediations of the social relationships, as well as the bases on which those mediations are established in the General of Balsas, are fundamentals for the understanding of the territorial reordenation happened in the referred area.

Key-words: Savannah. Public Politics. Territory. General of Balsas.

\section{Resumen}

En Brasil las formas de producción en el campo se encuentran cada vez más apoyadas en la revolución técnico-científica, aspecto ese que se acentuó a partir de la década de 1970, periodo en que el Gobierno Militar implementó políticas públicas para la expansión de la frontera agrícola y consecuentemente de la ocupación del Cerrado y de la Amazônia brasileña. Son espacios produtivos articulados a la lógica global de produtividade que posee como objetivo principal la producción de granos. La región de los Generales de Balsas se caracteriza como uno de esos espacios, evidenciado por el intenso uso de máquinas, insumos y fertilizantes, que permiten un nuevo uso del tiempo y del espacio. Estudiar las mediaciones de las relaciones sociales, así como las bases sobre las cuales esas mediaciones están establecidas en

\begin{tabular}{|l|c|c|c|c|c|c|}
\hline Boletim Goiano de Geografia & Goiânia - Goiás - Brasil & v. 29 & n. 1 & p. 73-86 & jan. / jun. & 2009 \\
\hline
\end{tabular}


los Generales de Balsas, son fundamentales importancia para la comprensión del (re)ordenamiento territorial ocurrido en la referida áre

Palabras clave: Cerrado. Políticas Públicas. Territorio. Generales de Balsas.

\section{Introdução}

A região dos Gerais de Balsas no Sul do Maranhão (figura 1), teve sua ocupação em um primeiro momento, (se desconsiderarmos os autóctones) caracterizada pela procura de terras disponíveis para criação de gado à solta, por criadores originários de outros estados do Nordeste, principalmente da Zona da Mata, região destinada ao cultivo de cana-de-açúcar no século XIX.

A partir do final da década de 1970, esse espaço começa a sofrer significativas transformações, devido, em grande parte, às ações governamentais de ocupação da fronteira agrícola. Verifica-se, a partir daí, a chegada de um fluxo migratório, principalmente de sulistas, que trazem consigo novas formas de trabalhar a terra, baseadas no uso de técnicas avançadas, culminando no processo de modernização da agricultura. Assim, novos arranjos são (re)criados no território balsense, inserindo-o no contexto da lógica global, que possui como objetivo principal a produção de grãos, sendo a soja o cultivo propulsor das transformações espaciais.

Todo esse contexto, causador de um (re)ordenamento na região, provoca questionamentos sobre a apropriação, a construção e o uso do território. As novas concepções sobre essa dinâmica nos levam a refletir sobre as relações de poder que se instalaram na localidade em que os processos territoriais vinculados ao capital se caracterizam como preponderantes. Neste contexto, os Gerais de Balsas-MA evidenciam um conjunto de novas ações e de novos objetos técnicos, atores sociais, políticos e econômicos, que fazem uso desses objetos e criam condições para a sua reprodução.

Para a construção deste trabalho utilizamos os seguintes métodos: pesquisa e observações in loco, com entrevistas informais, coleta de materiais bibliográficos, registros fotográficos e gravações. Dentre os resultados obtidos, podemos destacar que o território balsense encontrase articulado à dinâmica de produção inserida no meio técnico-científico-informacional, com a participação direta do Estado, instalação na localidade de fixos, com vista a favorecer os fluxos, crescimento urbano, mobilidade do trabalho e a presença de um grande número de pessoas 
exclusas do processo de modernização, inserida na localidade, com o advento da sojicultura.

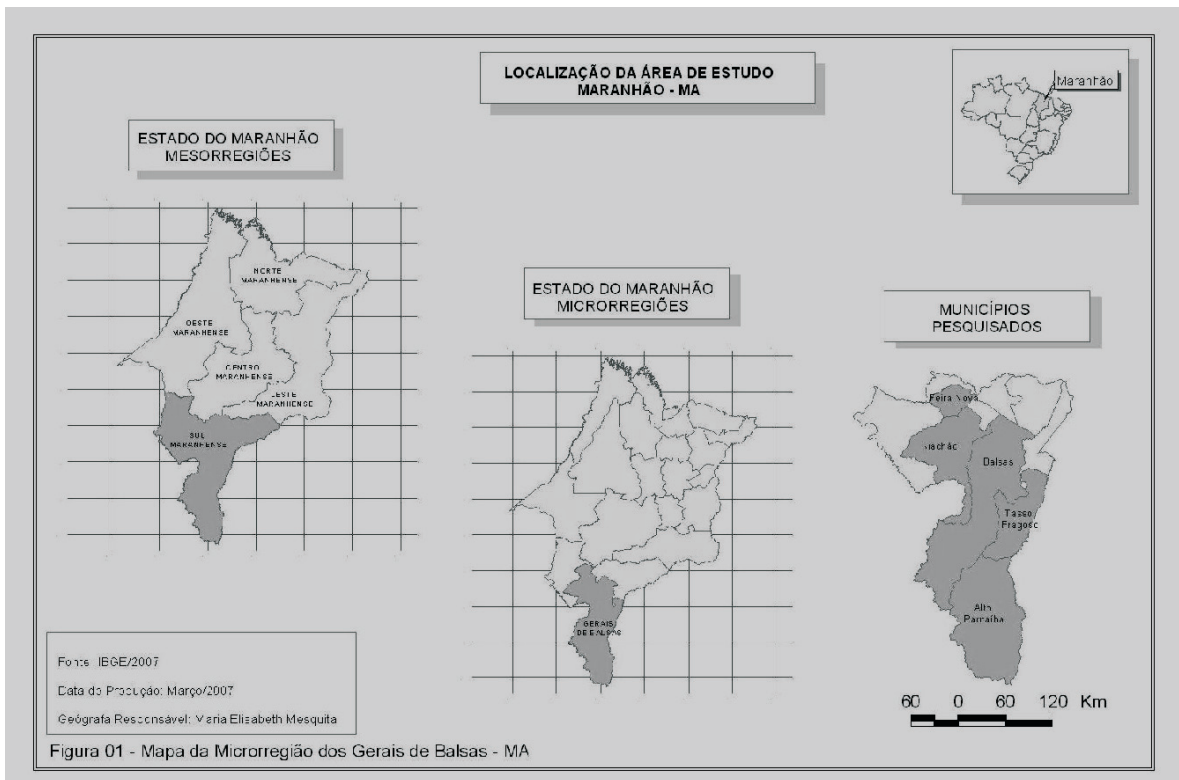

Sobre a estruturação deste trabalho, dividimo-lo em duas partes, onde a primeira objetiva desvendar as tramas e as teias traçadas pelo capital agroindustrial no espaço agrário brasileiro e, mais especificamente, na região dos Gerais de Balsas, Sul Maranhense, advindo da implantação de técnicas modernas de produtividade. Já na segunda parte, buscamos demonstrar, como tais pressupostos se apresentam em Balsas, através de dados colhidos juntos ao IBGE (Instituto Brasileiro de Geografia e Estatística), e à FAPCEN, (Fundação de Apoio à Pesquisa no Corredor de Exportação Norte).

\section{A modernização agrícola brasileira e suas inserções nos Gerais de Balsas-MA}

A partir da segunda metade do século XX, a agricultura brasileira passa a apresentar novas características, e as especializações técnicas, científicas e organizacionais se articulam para criar novos usos do tempo 
e do espaço. Estas configurações geram novos pressupostos sócioespaciais, ou seja, o espaço agrário brasileiro passa a apresentar uma nova moldura na sua estrutura territorial. Vale ressaltar que tais mudanças são fruto de políticas implementadas desde a década de 1930 pelo Estado Novo, com vistas a um novo dinamismo territorial no Brasil. Destacando-se a marcha para o oeste, protagonizada ainda no governo de Getúlio Vargas, onde este lançou mão de uma iniciativa de ocupação direcionada para o centro-oeste do Brasil, a partir da criação das Colônias Agrícolas nos estados de Goiás e do Mato Grosso.

A esses pressupostos, vinculou-se a denominada modernização ou industrialização da agricultura brasileira. Entretanto, Kageyama (1990, p. 44) chama atenção para as diferenciações existentes entre modernização e industrialização da agricultura. Para a autora, a modernização não representa um fenômeno recente, já que este aspecto se relaciona às transformações na forma de produzir, havendo assim a substituição de determinadas culturas por outras e, dentro da mesma cultura, por outras variedades modernas. O que há de fato, a partir da década de 1960, é uma mudança da base técnica - modernização - que culminou na própria industrialização da agricultura, conhecida também como modernização da agricultura via CAI (Complexos Agroindustriais), que para Delgado (1985) apud Mazzali (2000, p. 18), "possui como característica central o aprofundamento das relações do setor agrícola com a economia urbano-industrial e com o setor externo".

Seguindo essa perspectiva, o termo modernização será utilizado neste texto para designar o processo de transformação na base técnica da produção agropecuária no pós-guerra, a partir da junção de agricultura com a indústria, culminando também nas importações de tratores e fertilizantes, num esforço de aumentar a produtividade agrícola.

Toda essa transformação ocorrida se traduz pela implantação de técnicas modernas no espaço agrário do Brasil, gerando um processo de industrialização da agricultura que veio como resultado das transformações ocorridas a nível mundial através da "Revolução Verde ${ }^{1}$ ", tendo a soja como carro chefe desse processo.

Há ainda as mudanças relativas à divisão do trabalho no interior dos estabelecimentos agrícolas, além da instalação de um conjunto de eventos no espaço geográfico com vistas a favorecer os fixos e os fluxos ${ }^{2}$. Neste contexto, aumenta-se a possibilidade de aproveitamento dos solos menos férteis, antes desprezados para tal atividade. Esses processos se resumem em estratégias político-governamentais, tendo como objetivo principal a ocupa- 
ção das áreas consideradas "vazias" vigente que culminou na expansão da fronteira agrícola no país. Sobre este aspecto, Gonçalves Neto (1997, p. 122) faz a seguinte análise:

[...] a política agrícola colocada em prática pelo governo brasileiro, no período estudado, terá por objetivo básico manter inalteradas as formas de acumulação dominante na sociedade, compatibilizando interesses díspares de setores que lutam pelo controle dos principais fatores econômicos. Promove, portanto, a modernização de grande parte da agricultura, aumenta a produção e a produtividade sem, contudo, tocar nos padrões de acumulação.

Diversamente do que ocorria com os complexos rurais, o caráter natural e artesanal da produção passa a dar lugar à tecnificação das atividades agrícolas pela via de sua progressiva mecanização e quimificação, alterando, portanto, a própria maneira de produzir. Incluem-se aí novos produtos à pauta da produção agrícola, e ainda, novas variedades mais especializadas desses produtos passam a ser incorporados ao processo produtivo. Há também substituição da importação de alguns produtos agrícolas, e em especial, dos meios de produção para a agricultura (MAZZALI, 2000 p, 19).

Desta forma, entende-se que passou a existir a construção de um novo arranjo, tanto espacial quanto temporal, associado à possibilidade de incorporação dos procedimentos e métodos científicos para a realização da produção. Corroborando esta ideia, Elias (2006, p. 28) sugere:

As novas possibilidades de fluidez do espaço, somadas às que a revolução tecnológica vem propiciando à intensificação da forma de produzir na agropecuária, promovem verdadeira reestruturação produtiva no setor. A partir dessa reestruturação, muitos novos espaços agrícolas podem ser incorporados à produção e ao consumo agropecuário globalizados.

Essas transformações configuram, em seu conjunto, a partir da segunda metade dos anos 1960, um novo "padrão de desenvolvimento rural" que se consolidou mediante a onipresença do Estado (MAZZALI, 2000). Dentro desse contexto, insere-se o II PND - Plano Nacional de Desenvolvimento. Sendo que, para a execução da estratégia de desenvolvimento para o setor agropecuário, o Plano devia compreender ainda as seguintes áreas de atuação, a saber: I - Política de uso da terra para fins agropecuários; II - Esforço de modernizar e de dotar de bases empresariais o setor agropecuário, principalmente no Centro-Sul; III - Execução da reforma agrária e de programas de redistribuição de terras; IV - Estratégia de ocupação de no- 
vas áreas; V - Continuação da política de implantação de novas estruturas de abastecimento; VI - Fortalecimento da ação do setor público relativo a áreas indelegáveis; VII - Formação de estoques reguladores; VIII - Concentração setorial de incentivos; IX - Estratégia social para o setor rural.

Nesses itens, percebe-se uma organização governamental voltada para a reprodução do setor agropecuário brasileiro. No entanto, a reestruturação espacial, com todas as possibilidades advindas da revolução tecnológica, processou-se de forma seletiva e socialmente excludente, na medida em que manteve intocáveis as estruturas sociais, territoriais e políticas. Essas ações privilegiaram determinados segmentos e espaços mais suscetíveis de uma reestruturação sustentada a partir dos interesses e necessidades da globalização da produção e do consumo. Promove-se, nesta perspectiva, um crescimento econômico cada vez mais desigual, gerador de desequilíbrios, exclusão e pobreza, acentuando as históricas desigualdades sócio-espaciais brasileiras. Neste enfoque, Mendonça (2004, p. 80) aponta:

\footnotetext{
A crescente produção e produtividade de grãos no país, precisamente nas áreas anteriormente cobertas pela vegetação de Cerrados, não coaduna com a miséria e a fome alarmante na sociedade brasileira, especificamente, na área da pesquisa. O discurso da modernização da agricultura é cada vez mais forte, porém frágil, na medida em que não apontam soluções viáveis para milhares de trabalhadores desterritorializados no país.
}

A inserção dos lugares de reserva dos Cerrados e da Amazônia brasileira, destinados à produção agropecuária baseia-se muito no modelo econômico predominante nas últimas décadas. A intensificação desse modelo ocorreu nos governos militares com a política de integração nacional, sendo o Estado articulador desse processo. Esse pressuposto é visto ainda nos governos que se seguiram através das privatizações, que culminaram no acirramento do neoliberalismo e na diminuição do papel do Estado como responsável pela construção de um projeto de nação.

O estado do Maranhão, especificamente a região Sul maranhense ira conhecer, a partir da década de 1980, o incremento de políticas destinadas à manutenção do regime fundiário vigente. Só que agora, de forma mais acentuada tanto no tempo quanto no espaço, dadas as técnicas de produtividade inseridas a partir da modernização da agricultura. A dinâmica de modernização territorial insere o referido estado em um novo cenário político, econômico e social, através de modificações tanto de caráter interno como externo, articulando-o ao processo que se convencionou chamar de globalização. 
O contexto em que se insere o Maranhão hoje não se explica por si só, uma vez que existe um emaranhado de situações que viabilizaram a construção da estrutura vigente. Exemplos disso são as políticas nacionais e estaduais que incluem o território maranhense como pertencente à área de fronteira e, por isso, faz parte de projetos direcionados à sua entrada em um "novo tempo”, de dinamismo e desenvolvimento econômico e social através dos grandes projetos. As relações econômicas e sociais que envolvem a fixação de novos atores no sul maranhense estão inseridas nos meandros que impulsionaram e provocaram a expansão da fronteira agrícola no Brasil e que, com o apoio do Estado encontraram lugar propício de reprodução nos Gerais de Balsas através da existência, nessa localidade, de grandes extensões de terras devolutas (sem registro algum) que quando pertenciam a alguém, o preço era irrisório se comparado ao de outras regiões do país com estrutura fundiária já consolidada.

Conhecer os fatores propiciadores do cultivo da soja em Balsas passa, necessariamente, pelo entendimento das políticas e das ações em nível regional e estadual que impulsionaram o cultivo da soja. Segundo Ferreira (2006,p.155) a implantação da oleaginosa no Maranhão pode ser explicada “[...] pela situação em que se encontrava inserida a economia desse estado em relação ao setor produtivo. Ou seja, necessitando de investimentos. Assim, o governo é pressionado a buscar possibilidades alternativas para soerguer o setor de produção agrícola”. Dentre as ações do Estado facilitadoras da instalação das tecnologias capitalistas no Sul do Maranhão, destaca-se a implantação da BR-230 (Transamazônica); a criação da BR-153 (BelémBrasília); construção da Estrada de Ferro Carajás e os terminais portuários de Ponta da Madeira e de Itaqui em São Luís.

Um outro elemento a se considerar, foi a instalação do Prodecer III (Programa de Desenvolvimento do Cerrado) ${ }^{4}$, numa área que compreende a Batavo, no município de Balsas, sendo que tal localidade foi, em época anterior à instalação do projeto, alvo de conflitos através da grilagem de terras, objetivando a venda a grupos estrangeiros. Toda essa dinâmica foi e é geradora da expropriação da população pobre e da concentração e especulação fundiária.

Apesar de todo o discurso de modernização ocorrido na região, entendemos que o foco central dos projetos, aí empreendidos, encontra-se em favorecimento dos grupos que produzem em grande escala, mas que não geram emprego para a população local. Assim, fica o questionamento sobre o que significa desenvolvimento se a população em geral não se encontra inclusa no processo. No item a seguir, trataremos das transformações 
ocorridas nos Gerais de Balsas, para isso elencaremos alguns elementos que propiciaram essas transformações, e ainda, analisaremos as variáveis dos principais produtos cultivados na região.

\section{Balsas: um pólo sojicultor no sul do Maranhão}

No sul do Maranhão, as atividades de base agrícola, da mesma forma que ocorreu em boa parte das áreas de Cerrado no Brasil, foram também impulsionadas pelo Estado. Destacam-se neste caso, os incentivos disponibilizados pela SUDENE (Superintendência de Desenvolvimento do Nordeste) através dos programas de desenvolvimento regional. Lavouras de soja foram implantadas, e um novo arranjo territorial se formou na região. A topografia plana (maior parte), a grande disponibilidade de terras devolutas, a disponibilidade de recursos hídricos, presença de mão-de-obra barata favoreceram a implantação e os investimentos nas lavouras mecanizadas.

Partindo de um enfoque linear de acordo com a FAPCEN (2007), em relação as transformações ocorridas na área em estudo, pode-se fazer uma análise baseada na prerrogativa exposta no quadro a seguir:

Quadro 1 -Variação nos modos e meios de produção agrícola em Balsas de 1970 até os dias atuais.

\begin{tabular}{|c|c|c|c|}
\hline Anos70 & Anos 80 & Anos 90 & Atualmente \\
\hline $\begin{array}{l}\text { Roça de subsis- } \\
\text { tência (toco) } \\
\text { - Chegada dos su- } \\
\text { listas } \\
\text { - Sem infra-estru- } \\
\text { tura } \\
\text { - Arroz (cultura } \\
\text { predominante) } \\
\text { - Aleopatia = nô- } \\
\text { made }\end{array}$ & $\begin{array}{l}\text { - Início de entrada } \\
\text { de milho e soja } \\
\text { - Falta de crédito } \\
\text { - Falta de tecnologia } \\
\text { - Infra-estrutura } \\
\text { deficitária } \\
\text { - Mercado consumi- } \\
\text { dor limitado } \\
\text { - Criação do Corre- } \\
\text { dor de Exporta- } \\
\text { ção Norte e en- } \\
\text { trada da Embrapa } \\
\text { (final da década) }\end{array}$ & $\begin{array}{l}\text { - Atuação efetiva } \\
\text { da Embrapa } \\
\text { - Criação da Fap- } \\
\text { cen } \\
\text { - Melhoria da } \\
\text { Infra-estrutura } \\
\text { - Entrada das } \\
\text { Tradings (Bun- } \\
\text { ge, Cargill) } \\
\text { - Melhoria do } \\
\text { Crédito }\end{array}$ & $\begin{array}{l}\text { - Região consoli- } \\
\text { dada no cená- } \\
\text { rio nacional } \\
\text { - Infra-estrutura } \\
\text { de apoio re- } \\
\text { gular } \\
\text { - Potencial de } \\
\text { crescimento } \\
\text { bom } \\
\text { - Localização } \\
\text { estratégica }\end{array}$ \\
\hline
\end{tabular}

Fonte: Fapcen - Fundação de Apoio à Pesquisa no Corredor de Exportação Norte, 2007.

Em relação ao exposto acima, fica constatado que na década de 1970 começam a chegar à região de Balsas/MA os novos atores, possuidores de grande importância nas modificações que, irão ocorrer no espaço geográfico a partir 
de então. Por outro lado, nota-se que embora os sulistas tenham chegado ao Sul do Maranhão ainda na década de 1970, foi nos anos 1980 que se começou o plantio da soja. Esse fato alcançou representatividade nos anos 1990, com a chegada de apoio técnico-científico da EMBRAPA (Empresa Brasileira de Pesquisa Agropecuária) e da FAPCEN; de investimentos estaduais no tocante à infraestrutura, através do Corredor de Exportação Norte; da chegada das tradings (Bunge e Cargill) e da melhoria de créditos via BNDES (Banco Nacional de Desenvolvimento) Banco do Brasil e Banco do Nordeste.

Um aspecto importante foi a adoção de fortes incentivos por parte do Governo Maranhense, que para Lemos (2000 p. 20), "se traduzem na forma de renúncia fiscal e pela criação de infra-estrutura com recursos orçamentários provenientes do setor público". Esses incentivos contribuíram para que a soja se expandisse de maneira espetacular pelo Cerrado sul maranhense. Tal fator pode ser constatado através de uma análise da estrutura de produção das principais lavouras temporárias registradas nos Censos Agropecuários do Maranhão a partir dos anos setenta. Pela tabela 1, observa-se que apenas a partir da safra 1985 houve o registro de plantio da soja em áreas de 7.189 hectares que produziram 8.089 toneladas, sendo que nos anos seguintes registrou-se um aumento substancial na produção.

Tabela 1 - Áreas (ha) ocupadas e produção (ton.) das principais lavouras temporárias do Maranhão entre os Censos Agropecuários de 1970 e 2006

\begin{tabular}{c|c|c|c|c|c|c|c|c}
\hline \multirow{2}{*}{ Ano } & \multicolumn{2}{|c|}{ ARROZ } & \multicolumn{2}{c|}{ FEIJ̃̃O } & \multicolumn{2}{c|}{ MILHO } & \multicolumn{2}{c}{ SOJA } \\
\cline { 2 - 9 } & Área & Prod. & Área & Prod. & Área & Prod. & Área & Prod. \\
\hline 1970 & 482.271 & 650.852 & 74.774 & 22.351 & 360.769 & 136.045 & ------ & -------- \\
\hline 1975 & 614.974 & 894.165 & 53.645 & 21.929 & 358.436 & 147.329 & ------ & -------- \\
\hline 1980 & 737.753 & 1.026 .084 & 91.289 & 30.402 & 416.541 & 163.617 & ------- & --------- \\
\hline 1985 & 636.219 & 799.322 & 79.891 & 25.744 & 431.215 & 209.138 & 7.189 & 8.089 \\
\hline 1990 & 690.495 & 464.796 & 105.307 & 40.092 & 499.091 & 135.856 & 15.303 & 4.176 \\
\hline 1995 & 783.703 & 951.579 & 118.023 & 42.007 & 649.669 & 361.112 & 87.690 & 162.375 \\
\hline 2000 & 478.839 & 727.442 & 70.744 & 31.481 & 319.759 & 322.264 & 178.716 & 454.781 \\
\hline 2006 & 507.446 & 702.224 & 85.606 & 40.561 & 366.513 & 426.203 & 383.284 & 931.142 \\
\hline
\end{tabular}

Fonte: IBGE - Instituto Brasileiro de Geografia e Estatística.

A área direcionada à produção de arroz, no espaço de tempo compreendido entre 1970 e 2006, oscilou entre 48227 mil hectares e 507.44 mil hectares. Neste mesmo período, as áreas com feijão, mandioca e mi- 
lho oscilaram entre 74,77 mil e 85.60 mil (feijão); 154.15 mil a 212.09 mil (mandioca); e 360.77 mil e 366.51 mil (milho). Pode-se observar então uma pequena mudança nas áreas destinadas às lavouras temporárias tradicionais (tanto para mais quanto para menos) e um substancial acréscimo das áreas cultivadas com a soja no Maranhão. Ainda há de se destacar que o cultivo do arroz no Sul do Maranhão sofreu diminuição pelo fato de a prioridade passar a ser a produção/exportação e, nesse sentido, a soja encontra uma maior relevância no mercado externo. Mas, o arroz também é plantado no estado em grandes extensões, com a função de ser comercializado com as outras regiões do país.

Sobre os municípios produtores da soja no Sul do Maranhão, o destaque encontra-se em Balsas (tabela 02), local em que se concentra a maior produtividade e onde estão assentadas as empresas destinadas ao suporte na reprodução do espaço agrícola.

Tabela 02 - Produção (t) e área plantada (ha) da mesorregião sul-maranhense e do município de Balsas - 1980 a 2006

\begin{tabular}{c|c|c|c|c}
\hline \multirow{2}{*}{ Ano } & \multicolumn{2}{|c|}{ Mesorregião Sul-Maranhense } & \multicolumn{2}{c}{ Município de Balsas } \\
\cline { 2 - 5 } & Produção & Área Plantada (ha) & Produção (t) & Área Plantada (ha) \\
\hline 1980 & 96 & 80 & 96 & 80 \\
\hline 1985 & 9.008 & 8.127 & 1.813 & 1.511 \\
\hline 1990 & 4.176 & 15.230 & 1.607 & 5.952 \\
\hline 1995 & 162.303 & 87.213 & 36.794 & 19.889 \\
\hline 2000 & 448.359 & 176.370 & 152.141 & 60.040 \\
\hline 2003 & 637.289 & 266.306 & 216.053 & 89.278 \\
\hline 2006 & 824.759 & 349.127 & 246.468 & 108.100 \\
\hline
\end{tabular}

Fonte: Ferreira, 2006

Em âmbito geral, a sojicultura nos Gerais de Balsas tem colocado esta região como um pólo de desenvolvimento, ligado tanto ao mercado nacional como internacional. Pois a produção dessa leguminosa, ao contrário, da produção feita anteriormente (o arroz) nos complexos rurais, já nasce inserida no modelo de exportação, precisando, portanto, ser organizada em uma escala de produção capaz de concorrer no mercado internacional. Esse modelo tecnológico se estrutura sob três elementos básicos, o mecânico, o químico e o biológico, que atuam como economizadores de terra e mão-de-obra e como potencializadores de variedades mais produtivas. 
À luz dessas perspectivas se configuram as modificações no território balsense na década de 1970 em diante, que se dá pela utilização de novos objetos técnicos, marcando uma (re)estruturação das relações econômicas e sócioespaciais na localidade. Não obstante, o discurso de um desenvolvimento, que supostamente tenha ocorrido em Balsas como resultado da produção da soja, mascara os diversos problemas que já existia, se focarmos para o social e que se estende hoje para o ambiental.

A modernização vem imbuída de transformações que ocorrem de forma conduzida socialmente e desigualmente no tempo e no espaço. "É um processo contínuo de reestruturação societária, uma mudança da natureza, que afeta toda a sociedade” (HARVEY, 1993 p. 32). O espaço é reflexo dessas contradições materializadas pelas formas aí impregnadas condizentes com as funções específicas.

É claro que frente às mudanças surgem movimentos contrários, que decorrem como sintomas da crise e apontam perspectivas novas de reprodução social. Em Balsas, esse cenário ganha corpo através das instituições que se opõem ao modelo de produtividade em grande escala para servir, prioritariamente, à exportação. Dentre essas instituições, tivemos acesso à Associação Camponesa ,à Pastoral do Migrante e à Comissão Pastoral da Terra, que desenvolvem trabalhos no sentido de conscientizar os trabalhadores sobre a exploração e os maus tratos cometidos contra os mesmos. Objetiva também cobrar dos órgãos governamentais medidas paliativas para os problemas existentes na região relacionados a conflitos por terras, moradia, acesso à saúde, educação, etc.

Assim, aos poucos vai se construindo uma legitimidade social, para tentar de fato barrar o processo de exclusão social que assola não somente essa parte do Maranhão, mas é uma questão que perdura na maior parte do estado e do país.

\section{Considerações finais}

Os Gerais de Balsas encontram-se envoltos numa complexa trama, em que as marcas espaciais aí estabelecidas revelam as ações que o capital cria e usa para se reproduzir e se consolidar. São fatores históricos construidores de territórios que se re-estruturam continuamente. Não obstante, essa construção obedece a uma lógica, que é a lógica da reprodução ampliada e seletiva dos meios de produção, precarização 
do trabalho e exploração e expropriação de imensa quantidade de trabalhadores.

Neste contexto, encontra-se a modernização da agricultura, através da sojicultura, que colocou Balsas como um pólo econômico no Maranhão. Entende-se que essa especificidade deu um novo viés à região, como: crescimento econômico, aumento da população, fixação de empresas comerciais e financeiras, chegada de novos atores (sulistas). Entretanto, pouco se coloca das contradições aí estabelecidas. E então surge um questionamento que parte da seguinte prerrogativa: A soja trouxe para Balsas todo um conjunto de modificações que a articulam ao mercado nacional e internacional, então, por que tantas críticas a esse modelo de produtividade? As críticas se assentam justamente pelo fato de como se faz esse tipo de cultivo, para onde vai a produção e quem ganha e perde com tudo isso.

Sobre as peculiaridades contidas hoje em Balsas, podemos ressaltar que a modernização agrícola veio acompanhada de atores propiciadores desse processo, o migrante sulista. Não obstante, entendemos que o que insere essa região nos mecanismos da modernização não é o migrante sulista e nem a soja. Isso se deve, principalmente ao capital monopolista, detentor da ordem implantada na contemporaneidade, que através dos meandros e das teias traçadas pelos atores aí estabelecidos encontram no pólo de Balsas lugar propício para a sua reprodução. Insere-se aí as redes de integração espacial, a mobilidade do trabalho e a fixação de corporações agroindustriais e financeiras nacionais e internacionais, tudo isso provoca um re-desenhar espacial, constituindo um re-ordenamento territorial, com novas relações de poder próprias da contemporaneidade.

Claro que essas bases se assentam num construto onde a dialética é uma constante, já que a estrutura espacial demonstra as contradições inerentes a esse processo. Então, ao lado do crescimento econômico surge o desemprego. Por isso dizer que a instalação do capitalismo em sua forma dominante se dá de maneira desigual e combinada. Desigual, porque poucos lucram, e combinada porque deixa em seu rastro uma massa de excluídos ávidos por fazerem parte do processo modernizante.

1 Define-se "Revolução Verde" como modelo de intensificação do desenvolvimento agrícola, com o objetivo de aumentar a produção via a implementação de uma série de inovações tecnológicas, tais como sementes geneticamente melhoradas, uso intensivo de insumos agroquímicos e desenvolvimento da mecanização e irrigação em grande escala (THEODORO, LEONARDOS \& DUARTE, 2002).

2 Território e Espaço não são termos análogos, já que ora ou outra, tais conceitos parecem se 
confundir mutuamente. Sobre esse aspecto Raffestin (1993, p. 143) faz a seguinte colocação: "espaço e território não são termos equivalentes, sendo essencial compreender que o território se forma a partir do espaço, sendo este o resultado de uma ação conduzida por um ator sintagmático". Assim, território se constitui em um conceito subordinado à organização espacial, revestido de dimensões políticas e simbólicas, onde as práticas sociais se formam a partir de uma dialética constante pela produção do/no espaço.

3 Segundo Becker (1997, p. 10) "a noção de 'espaço vazio' serve estrategicamente de válvula de escape para investimentos em áreas em que o capital ainda não se estruturou” A autora neste caso, fala a respeito da Amazônia que não se constituía de fato numa região de espaços vazios, pois aí já estavam estabelecidos os indígenas e os camponeses que se dedicavam ao extrativismo ou ao cultivo de seus roçados.

4 No Brasil, este tipo de cultura, avançou pelos Cerrados, principalmente com a implantação do POLOCENTRO (Programa de Desenvolvimento dos Cerrados), pelo PRODECER (Programa Nipo-brasileiro de Cooperação para o desenvolvimento do Cerrado). Em suas versões I, II e III esse programa avançou desde o Sudeste e Centro-Oeste, chegando até os Cerrados nordestinos, como se verifica no Oeste Baiano, Sul do Maranhão e Sul do Piauí.

\section{Referências}

BECKER, Bertha K. Amazônia. 5. ed. São Paulo: Ática, 1997.

ELIAS, Denise. Agronegócio e desigualdades socioespaciais. In: ELIAS, Denise; PEQUENO, Renato. (Orgs.) Difusão do agronegocio e novas dinâmicas sócio espaciais. Fortaleza: Banco do Nordeste, 2006.

FAPCEN, Fundação de apoio à pesquisa no corredor de exportação Norte - Relatório 2007.

FERREIRA, M. da G. Re-organização do espaço a partir da produção de soja: Balsas-MA. In. Terra Livre. v. 2, n. 27, Presidente Prudente, 2006.

GONÇALVES NETO, Wenceslau. Estado e agricultura no Brasil: Política Agrícola e Modernização Econômica Brasileira 1960 - 1980. São Paulo: Hucitec, 1997.

IBGE - Instituto Brasileiro de Geografia e Estatística. Censo agropecuário 2006/2007.

HARVEY, David. A condição pós-moderna. 11. ed. São Paulo: Edições Loyola, 2002

II PND. Plano nacional de desenvolvimento. São Paulo: Sugestões literatas, 1975.

KAGEYAMA, Ângela. O Novo Padrão Agrícola Brasileiro: Do complexo Rural aos Complexos Agroindustriais. In: KAGEYAMA, Ângela e SILVA, J. G. da (Orgs.). Agricultura e Políticas Públicas. Brasília: Série IPEA n 127, 1990.

LEMOS, José de Sousa. O cultivo da soja no sul do Maranhão: implicações ambientais, sociais e econômicas. Pesquisa em Foco. São Luis; v. 1, n. 1, UEMA/PPG, 2000.

MAZZALI, Leonel. O processo recente de reorganização agroindustrial: do complexo à organização em rede. São Paulo: Editora UNESP, 2000.

MENDONÇA, Marcelo Rodrigues. A urdidura espacial do capital e do trabalho no cerrado do sudeste goiano. Tese de doutoramento em geografia. Universidade Estadual Paulista: Presidente Prudente, 2004. 
RAFFESTIN, Claude. Por uma geografia do poder. São Paulo: Editora Ática, 1993.

THEODORO, Suzi Huff; LEONARDOS, Othon H. e DUARTE, Laura Maria Goulart. Cerrado: O Celeiro Saqueado. In: DUARTE, Laura Maria Goulart e THEODORO, Suzi Huff. (Org.). Dilemas do Cerrado: entre o ecologicamente (in)correto e o socialmente (in)justo. Rio de Janeiro. Garamond, 2002.

Rosimary Gomes Rocha - Mestre em Geografia e professora da Secretária Estadual de Educação do Tocantins.

Recebido para publicação em Setembro de 2008

Aceito para publicação em Março de 2009 